\title{
Shake-table response simulation of a URM building specimen using discrete micro-models with varying degrees of detail
}

\author{
Mattia Calò ${ }^{1} \cdot$ Daniele Malomo $^{2}$ (D) $\cdot$ Giammaria Gabbianelli ${ }^{3} \cdot$ Rui Pinho $^{1}$ (D)
}

Received: 21 May 2021 / Accepted: 9 August 2021 / Published online: 24 August 2021

(c) The Author(s) 2021

\begin{abstract}
Recent technological advances have enabled earthquake engineering researchers to develop numerical models of increasing complexity, capable of duly reproducing even the smallest structural detail. In the case of unreinforced masonry (URM) structures, however, because of their discrete and heterogeneous nature, computational performance tends to decrease exponentially as a function of the adopted refinement level, thus confining the applicability of advanced micro-models, according to which each masonry unit is typically modelled separately, to reduced-scale problems. To enable their use at a building scale, and benefit from considering simultaneously out-of-plane failures, local wall-diaphragm interaction and collapses, researchers often need to decrease the level of detail of specific members or sub-structures. In the current literature, however, the influence of the abovementioned simplifications on the quality of micro-modelling predictions has been only marginally investigated so far, while code-based guidelines are missing. To start addressing such knowledge gap, the dynamic response of a shake-table-tested full-scale URM building specimen has been simulated in this work using a very detailed micro-model, and the results obtained were then compared with those of nominally identical models in which, however, the idealisation of some specific structural elements has been purposely simplified. Aimed at further extending the impact of this study, pushover analyses were also performed using the same models. Preliminary outcomes, which may serve as a reference to develop more informed, effective and targeted multi-scale micro-modelling strategies in the future, indicate that: (i) maximum base shear predictions tend to be less impacted by the introduction of modelling simplifications, (ii) despite requiring more labour, the explicit representation of the brickwork pattern generally led to better results in terms of predicted damage propagation, failure mechanisms and displacement capacity, (iii) using equivalent membranes, as opposed to modelling each component of timber diaphragms, provided acceptable results, making it a plausible alternative for practical applications of micro-modelling approaches.
\end{abstract}

Keywords Unreinforced masonry (URM) - Shake-table testing · Discrete micromodelling $\cdot$ Applied element method (AEM)

Rui Pinho

rui.pinho@unipv.it

Extended author information available on the last page of the article 


\section{Introduction}

The numerical assessment of the seismic response of unreinforced masonry (URM) buildings is typically conducted using low-cost computational strategies, which allow the undertaking of a relatively large number of analyses in a reasonable timeframe. Simplified methods, ranging from the application of limit analysis (D’Ayala and Speranza 2003; Block et al. 2006) to story mechanism models (Braga and Dolce 1982; Tomaževič 1987) and equivalent single-degree-of-freedom systems (Graziotti et al. 2016; Snoj and Dolšek 2020), have been used over the years to study the structural behaviour of low-rise and regular masonry constructions subjected to either quasi-static or dynamic loading. Of particular interest are the latest developments in mathematical modelling and variational approaches (Portioli 2019; Cascini et al. 2020), incorporating principles of both limit and discontinuous analyses, although presently mainly applied to historic and dry-joint URM constructions (see e.g. Portioli et al. 2021).

Despite the use of various macroelement approaches, including those based on e.g. equivalent frame idealisations (Penna et al. 2014; Raka et al. 2015; Sangirardi et al. 2019), in presence of irregular opening layouts the identification of the effective wall height and the definition of rigid and deformable regions becomes non-unique and may lead to epistemic modelling errors (see e.g. Berti et al. 2017). Further, notwithstanding some recent promising upgrades to this initial scheme (e.g. Pantò et al. 2017; Malomo and DeJong 2020; Vanin et al. 2020), out-of-plane (OOP) modes are often neglected, thus confining the applicability of macroelement models to in-plane (IP) governed responses, as showed by Quagliarini et al. (2017). Similarly, although both experimental (e.g. Vasconcelos and Lourenço 2009) and numerical (e.g. Malomo et al. 2019) investigations have shown that masonry bond pattern might considerably affect the IP performance of URM members, this aspect is seldom accounted for numerically.

The aspects above, combined with the simplified modelling of diaphragms (which e.g. neglects local wall-to-diaphragm and wall-to-wall interactions), the inability to simulate responses beyond near-collapse, and the tendency to perform pushover analyses rather than considering dynamic loading, may result in unconservative predictions (Casolo and Uva 2013; Silva et al. 2019). More refined computational techniques have therefore been lately used for assessing the response of URM structures under earthquake actions. Various examples of Finite-Element (FE)-based meso-scale models for the numerical analysis (Aref and Dolatshahi 2013; Petracca et al. 2017; Saloustros et al. 2018) of both existing and historical URM constructions are presently available in literature. However, FE simulation of the structural behaviour of heavily damaged structures, i.e. when considering separation and collision among units becomes relevant, is often challenging due to nodal compatibility issues, as showed in Grunwald et al. 2018).

Recent technological advances, which have led to increased access to high computational power, have also enabled to further increase the level of complexity and detail through the use Discrete Element (DE) micro-models. Originally conceived for rock mechanics applications (Cundall 1971) and previously only considered for the modelling of reduced-scale problems due to the high computational expense, DE models have been recently employed for the seismic analysis of full-scale residential (Adhikari and D'Ayala 2020) and industrial (Karbassi and Nollet 2013) URM buildings made of either clay or stone units. In the DE framework, each unit is typically modelled separately, and connected to each other through zero-thickness interface springs, where damage occurs, and system nonlinearity is lumped (Pulatsu et al. 2016). Notwithstanding the possibility of representing explicitly fracture propagation and OOP 
failures, as well as both local and global collapses, the DE modelling of large-scale URM systems is still computationally unfeasible in many cases, and requires very specific user skills and a wide range of different material properties.

To take advantage of the unique capabilities of DE micro-models, and enable their use at a building scale, researchers often find themselves decreasing the level of detail of specific members or sub-structures, including floor and roof systems (Furukawa et al. 2010; Galvez et al. 2018), wall-to-wall and wall-to-diaphragm connections (Malomo et al. 2020a), as well as masonry panels (Pulatsu et al. 2020; Prakash et al. 2020). In the current literature, however, and as far as the authors are aware of, a systematic assessment of the influence of the abovementioned simplifications on the quality of micro-modelling predictions is presently missing, while the same applies to code-based modelling guidelines. Therefore, this research intends to investigate and quantify potential impacts on numerical accuracy of such simplifications through different numerical models in which the idealisation of some specific elements has been purposely simplified. To do so, a reference detailed DE micro-model implemented in the framework of the Applied Element Method (AEM) (Meguro and Tagel-Din 2000, 2001, 2002), was developed. The AEM model was calibrated against the experimentally-observed shake-table response of a full-scale URM building specimen. The obtained results were compared to each other in terms of overall base shear, displacement capacity, and damage evolution. To highlight further dissimilarities due to different modelling refinement levels, the influence of additional aspects, including e.g. damage accumulation and quasi-static vs dynamic loading type, were also investigated numerically. All models were developed using the software Extreme Loading for Structures (Applied Science International LLC. 2018).

\section{Applied element method for masonry micro-modeling}

According to the AEM, which can be classified as a rigid body and spring DE model (D'Altri et al. 2019), URM components are explicitly reproduced by representing the actual unit arrangement as an assembly of solid rigid bodies, connected by zero-thickness equivalent interface spring layers to which the unit-mortar interface properties are assigned, according to a simplified micro-modelling approach. With reference to the nomenclature depicted in Fig. 1a, each interface spring is characterised by a normal $\left(k_{n i}\right)$ and shear $\left(k_{s i}\right)$ stiffness Eqs. 1,2, where $E_{m}, G_{m}$ are masonry Young's and shear moduli respectively, while $j$ and $d$ stand for the spring number along $y$ and $z$-direction respectively.

It is worth noting that the equivalent interface spring stiffnesses were obtained assuming unit and mortar springs arranged in series at an arbitrary contact point. Such initial parameters, depending on the constitutive material laws selected, are modified at each timestep in order to account for the damage evolution.

$$
\begin{aligned}
& k_{n i}=\sum_{i=1}^{j}\left(\frac{E_{m} d\left(\frac{t_{u}}{j}\right)}{l_{u}}\right) \\
& k_{s i}=\sum_{i=1}^{j}\left(\frac{G_{m} d\left(\frac{t_{u}}{j}\right)}{l_{u}}\right)
\end{aligned}
$$




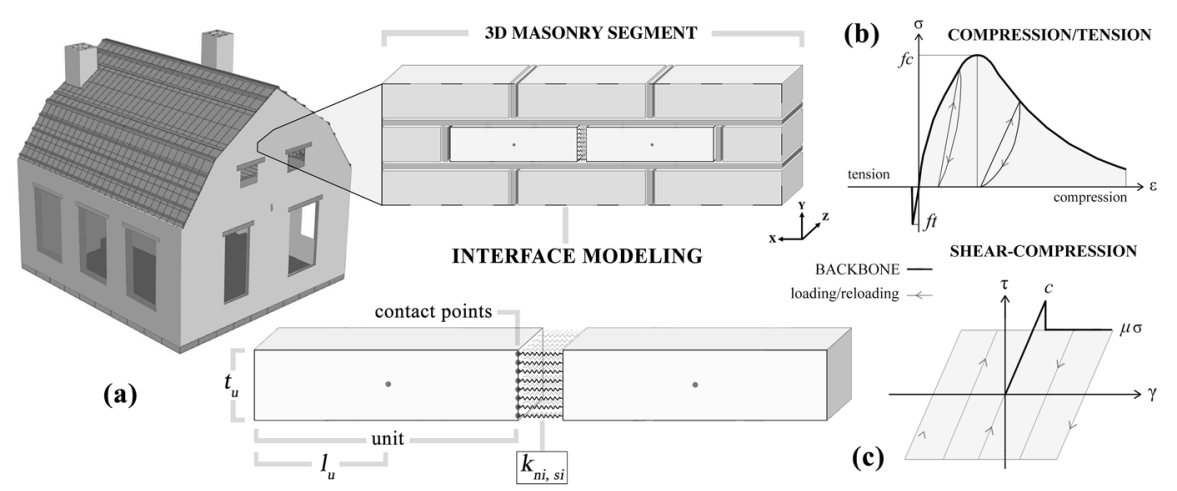

Fig. 1 a AEM discretization of a 3D masonry segment and normal/shear interface stiffnesses, b compression/tension and $\mathbf{c}$ shear-compression joint models

Within the AEM framework, unit, joint and combined modes are described using simplified constitutive laws: a simplified version of the elastic-perfectly-plastic fracture model conceived by El-Kashif and Maekawa (2004) is typically used for representing the effect of cyclic damage due to uniaxial compression loading (see Fig. 1b). A tension cut-off criterion (with no softening branch) characterises instead the spring response in tension/flexure, while shear-governed behaviours are reproduced using a Mohr-Coulomb-like model, where cohesion is set to zero right after reaching the maximum shear strength, as shown in Fig. 1c. It is noted that if springs fail in tension, they can still work in compression if the joint closes again. The constitutive laws described above and depicted in Figure (b, c) have been directly implemented in the numerical models developed in this work. Interested readers may refer to e.g. Malomo et al. $(2020 \mathrm{a}, \mathrm{b})$ for further details regarding how these expressions are employed depending on the considered failure mechanism, for the main differences with respect to more common FE approaches and other DE techniques, as well as for a comprehensive selection of numerical validation exercises against characterisation tests on small-scale assemblies, quasistatic IP and OOP experimental tests on components, full-scale shake-table tests on various URM building prototypes.

As showed in Malomo et al. (2018, 2020a), P-delta effects can also be accounted for numerically using the AEM. During the analyses carried out in this work, no external dynamic relaxation schemes were introduced, meaning that the only source of damping in the proposed numerical models is the energy dissipation due to difference in loading and unloading paths of compression springs, as well as that induced by the process of crack closure/opening. Recent applications, e.g. Papantonopoulos et al. (2002) and Calvi et al. (2019), have shown that this usually provides adequate results when considering the collapse modelling of both reduced and large-scale systems. Additional theoretical background, applications and discussions on the latter aspects are presented in Tagel-Din (1998).

\section{Detailed micro-modeling of a full-scale URM building specimen}

The development of a detailed AEM model, taken as a reference in this work for subsequent comparisons with simpler models devised in the same micro-modelling environment and presented in the next section, is herein described. The "reference" (or REF) 
model, whose main characteristics will be discussed further in what follows, along with the shake-table-tested URM building specimen selected for validation purposes, entails a very high number of rigid elements, i.e. 36'000, which translates in 220'000 degrees-offreedom (DOFs). To give a sense of the complexity and details of this model, it is noted that the AEM model developed by Malomo et al. (2020c) for simulating the collapse of the Morandi bridge comprised an analogous number of DOFs.

\subsection{Brief description of the shake-table-tested URM building specimen}

The full-scale building specimen considered in this work, hereinafter referred to as LNECBUILD3, was tested in 2019 on the shake-table of the LNEC laboratory (Laboratorio Nacional de Engenharia Civil, Lisbon, Portugal) under incremental uniaxial loading protocol (see Fig. 2a), in the framework of a larger research project aimed at investigating the potential effects on URM constructions of induced-seismicity phenomena due to gas extraction in the Groningen region, The Netherlands (Graziotti et al. 2019). As stated by the researchers who conducted the test (i.e. Kallioras et al. 2020), LNEC-BUILD3 was not necessarily intended to replicate the characteristics of an actual building, but rather to incorporate several main features of typical pre-1940 detached houses of the Groningen area (reported in the following), with a view to obtain multiple different insights from the response of the various sub-structures constituting the specimen. In terms of numerical analysis, this undoubtedly represents a unique opportunity to test the influence of different computational strategies at both local and global levels of various structural sub-systems, built in the same time period by the same masons, and tested simultaneously under the same loading conditions.

As shown in Fig. 2b, LNEC-BUILD3 consisted of a single-story full-scale URM building assembly, $5.66 \mathrm{~m}$ long, $5.44 \mathrm{~m}$ wide and $5.22 \mathrm{~m}$ high (ridge level; floor level is $2.72 \mathrm{~m}$ ) with a total mass of 30.3 tons, characterised by $208 \mathrm{~mm}$ thick double-wythe solid clay

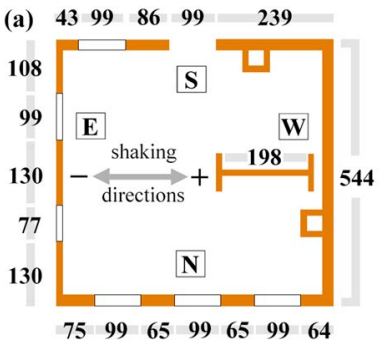

(d) RUNNING BOND

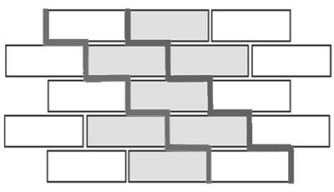

- possible crack paths through mortar joints
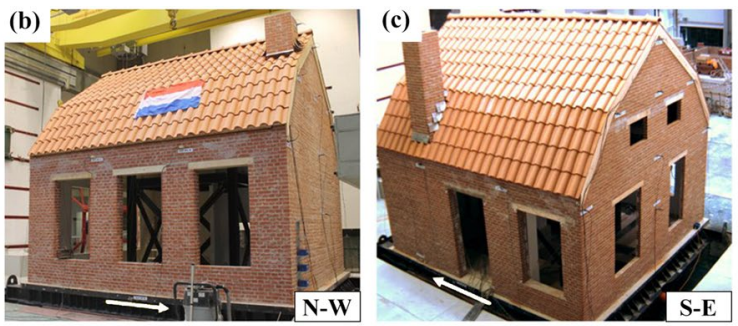

DUTCH CROSS-BOND
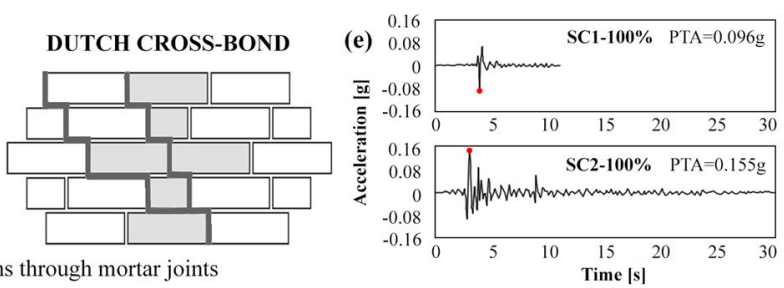

Fig. 2 a Plan (in $\mathrm{cm}$ ) of LNEC-BUILD3, photos of the specimen from $\mathbf{b} \mathrm{N}-\mathrm{W}$ and $\mathbf{c}$ S-E ( adapted from Kallioras et al. (2020), d standard running vs Dutch cross bond pattern, e unscaled SC1 and SC2 accelerograms and PTAs 
brick walls, large asymmetrical ground-floor openings on North and South façades, timber diaphragms (see Fig. 2c), and two chimneys of equal height (i.e. $5.28 \mathrm{~m}$ ) and flues (i.e. $0.34 \times 0.34 \mathrm{~m}^{2}$ ) located on the West and South walls, extending $0.06 \mathrm{~m}$ above the roof ridge and $2.3 \mathrm{~m}$ above the roofline and hereinafter referred to as tall and short chimney, respectively. The transverse East front panel, unlike the three other perimeter walls, consisted of a 100-mm-thick, single-wythe façade, with openings both on floor and roof levels, and characterised by a tall gable weakly connected to the roof framing. A 100-mm-thick interior wall was built parallel to the direction of shaking (i.e. West-East axis), lengthwise along the centreline of the building plan. The wall was $1.98-\mathrm{m}$ long, including two symmetric 0.75 -m-wide flanges, and did not extend over the floor. While a standard running bond pattern was used for the single-wythe walls, Dutch cross brickwork bond was adopted for the double-wythe ones. As depicted in Fig. 2d, the former is slightly different from the English bond in generating the lap at the quoins, as all quoins are three-quarter bats. This results in a steeper inclination of the stepped cracks through mortar in case of diagonal shear failure, with respect to both running and English brickworks.

The flexible timber floor was made of $190 \times 24 \mathrm{~mm}$ thick timber floorboards, nailed perpendicularly to nine $75 \times 180 \mathrm{~mm}$ timber joists spanning continuously between the North and South façades, and supported by a single central timber girder, pocketed in the East wall and eastern flange of the interior wall. The floor system, also considering the additional masses (provided by twelve $150-\mathrm{kg}$ heavy steel plates), weighed 2.51 tons. The halfhipped (jerkinhead) gambrel roof (total mass 3.01 tons) consisted of five South-North timber joists $(64 \times 114 \mathrm{~mm})$, which supported longitudinal East-West purlins $(44 \times 64 \mathrm{~mm})$ and a central ridge beam $(38 \times 120 \mathrm{~mm})$. With respect to the latter, continuous timber boards $(200 \times 18 \mathrm{~mm})$ were arranged perpendicularly and connected through a couple of $150 \mathrm{~mm}$-spaced $3 \mathrm{~mm}$ diameter nails. Finally, clay tiles, supported by a grid of laths and counter battens, were nailed on the top.

Two single-component, pulse-like earthquake accelerograms (see Fig. 2e), were selected for the uniaxial shake-table test: SC1, with absolute peak table acceleration PTA $=0.096 \mathrm{~g}$, and $\mathrm{SC} 2$, with $\mathrm{PTA}=0.16 \mathrm{~g}$. The latter signals were scaled (SC1 from 50 to 150\%; SC2 from 50 to 500\%) and consecutively applied until near-collapse conditions were reached. Since only minor damage was detected up until SC1-150\% included, the SC2 loading protocol alone was considered in this work for modelling purposes.

Interested readers are referred to the work of Kallioras et al. (2020), where construction details, experimental loading protocols and results, as well as their interpretation, are extensively discussed.

\subsection{Numerical idealisation of construction details}

The main features of the model are depicted in Fig. 3, along with their experimental counterparts. As per the masonry members, both running and Dutch cross bond patterns have been faithfully reproduced numerically. The reason for such a time-consuming modelling exercise is related to the fact that according to relatively recent experimental investigations (e.g. Vasconcelos and Lourenço 2009; Mojsilović 2011; Thamboo and Dhanasekar 2016), the brick/block arrangement may significantly affect the IP behaviour of URM members. Further, numerical studies (e.g. Malomo et al. 2019), have highlighted that Dutch cross bond pattern panels are more prone to brittle diagonal shear failures with respect to e.g. English and running brickworks, resulting in lower IP ultimate displacement capacity and sudden drops of lateral resistance after the base shear peak. As far as the authors are aware 


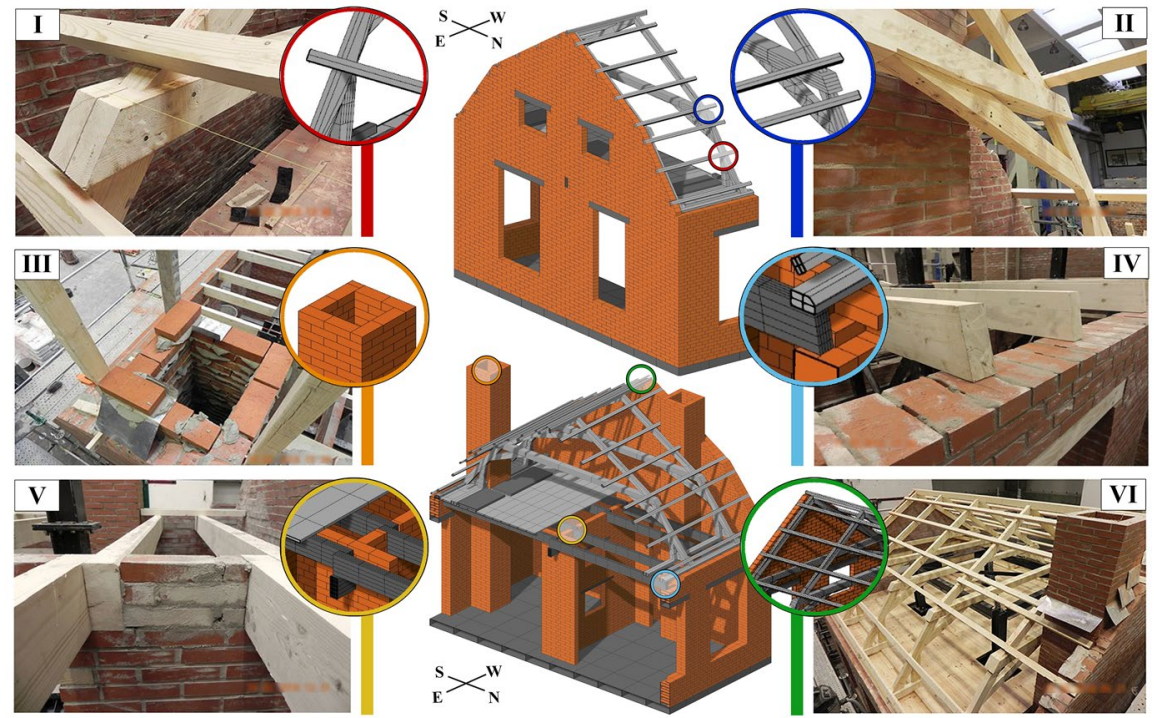

Fig. 3 Comparison between experimental construction details and numerical micro-modelling idealisation

of, potential consequences of the abovementioned aspects at the building scale are not yet available in literature. Interlocking among transversal and longitudinal façades at corners, as well as between chimneys and West/South walls, was explicitly modeled. Since the effect of brick failures was not particularly predominant in the response of LNEC-BUILD3, units were herein modeled as fully-rigid, without any internal subdivision. To each brickto-brick interface, 25 springs were allotted; this number, as shown in e.g. Malomo and DeJong (2021), is slightly larger than the minimum required for capturing the actual flexural strength and stiffness in case of rigid body and spring assemblies undergoing rocking and OOP modes.

Material properties of masonry were taken from characterisation tests carried out in the framework of the same research project, which involved (amongst others) uniaxial cyclic compression, bond wrench and shear-compression tests on small samples, thus yielding values of masonry compressive strength $f_{c}$, Young's modulus $E_{m}$, flexural bond strength $\mathrm{f}_{\mathrm{w}}$, cohesion $\mathrm{c}$ and friction coefficient $\mu$. The associated values, directly implemented into the AEM model and thus assigned to the spring layers among rigid units, are summarised in Table 1. Employed shear modulus $\mathrm{G}_{\mathrm{m}}$, not inferred experimentally, was conventionally set equal to $0.4 \mathrm{E}_{\mathrm{m}}$.

In the framework of the experimental campaign considered in this work, previous test results (see e.g. Tomassetti et al. 2019) indicated that the interaction among timber members and masonry elements influenced both damage propagation and gable-roof displacement capacity. Thus, in this specific case, the explicit representation of each component of the flexible diaphragms (i.e. boards, joists, purlins, etc. of both floor and roof) was deemed necessary to maximise numerical accuracy, even if it is recognised that such a detailed modelling approach is not typically employed in practical applications. Nonetheless, with a view to avoid the burdensome modelling of the actual distribution of nailed connections, as well as the employment of the corresponding complex nonlinear constitutive laws (which would have increased significantly the computational 
Table 1 Measured and inferred

\begin{tabular}{lcccccc}
\hline & $f_{c}$ & $f_{w}$ & $E_{m}$ & $G_{m}{ }^{*}$ & $c$ & $\mu$ \\
\hline Avg [MPa] & 11.5 & 0.36 & 9120 & 3648 & 0.47 & 0.81 \\
C.o.V. [\%] & 0.083 & 0.36 & 0.13 & - & - & - \\
\hline
\end{tabular}

*Masonry 1 material properties considered

Table 2 Inferred mechanical parameters assigned to floor and roof members

\begin{tabular}{lllllllllll}
\hline$\rho_{m}$ & $\phi$ & $s_{n}$ & $k_{\text {ser }}$ & $k_{\varphi}$ & $K_{\perp}$ & $K_{\|}$ & $E_{t}$ & $G_{t}$ & $G_{\perp}$ & $G_{\|}$ \\
\hline$\left[\mathrm{kg} / \mathrm{m}^{3}\right]$ & {$[\mathrm{mm}]$} & {$[\mathrm{mm}]$} & {$[\mathrm{N} / \mathrm{mm}]$} & {$[\mathrm{kNm} / \mathrm{rad}]$} & {$[\mathrm{kN} / \mathrm{m}]$} & {$[\mathrm{kN} / \mathrm{m}]$} & {$[\mathrm{MPa}]$} & {$[\mathrm{MPa}]$} & {$[\mathrm{MPa}]$} & {$[\mathrm{MPa}]$} \\
450 & 2 & 120 & 554 & 3.98 & 59.9 & 45.03 & 12,000 & 4800 & 5 & 11 \\
\hline
\end{tabular}

expense), a linear elastic modelling strategy was undertaken that makes use of codebased and analytical expressions to infer three main input parameters, namely $E_{t}, G_{t}$, $k_{\text {ser }}$, as described below. Interested readers may refer to Malomo et al. (2020a, b), where similar approaches are discussed in more detail.

- Linear elastic material (with Young's and shear moduli $E_{t}, G_{t}$, see Table 2) was assigned to all the main components (e.g. boards, joists, purlins, etc.) of flexible diaphragms, which were modelled as solid 3D elements (see Fig. 3).

- Based on experimental evidence (see e.g. Wilson et al. 2013), interlocking phenomena due to tongue and groove joint interfaces among timber boards were herein neglected.

- Since all joists were laid directly on the bricks in the building specimen, a no-tension Mohr-Coulomb model $(\mu=0.8, c=0)$ was assigned to the corresponding numerical interfaces. Standard masonry properties were assigned to the vertical joints, which were instead filled with mortar.

- To connect the timber boards to the joists and simulate the nonlinear response of nails in a simplified manner, use was made of equivalent springs with normal stiffness $k_{\text {ser }}$ equal to the nail slip modulus suggested by Eurocode 5 (CEN European Committee for Standardization; 2004) and computed according to Eq. 3, where $\rho_{m}$ represents wood density, $\phi$ is nail diameter, $s_{n}$ nail spacing. Using this approach, the spring layer produce an overall rotational stiffness $k_{\varphi}$, as shown by Eq. 4 from Gattesco and Macorini (2014).

$$
\begin{gathered}
k_{\mathrm{ser}}=\left(\frac{\rho_{m}^{1.5} \cdot \phi^{0.8}}{30}\right) \\
k_{\varphi}=\left(\frac{k_{0} \cdot s_{n}^{2}}{2}\right)
\end{gathered}
$$




$$
\begin{gathered}
K_{\perp, \|}=\frac{n_{j} n_{b} k_{\varphi}}{L_{\perp, \|}^{2}} \\
G_{\perp, \|}=\left(\frac{K_{d} H}{t_{b} B}\right)
\end{gathered}
$$

The use of the abovementioned local parameters resulted in the global IP stiffness $K_{\perp}$ and $K_{\|}$of timber floor and roof respectively, which can be also calculated analytically using Eq. 5, where $n_{j}$ and $n_{b}$ represent the number of joists and boards, respectively, and $\mathrm{L}_{\perp, \|}$ is the length of the diaphragm along either the shaking direction perpendicular (floor) or parallel (roof) to the joists. The associated shear modulus $G_{\perp, \|}$ can be determined with Eq. 6, where $B$ is the floor span length and $t_{b}$ the board thickness; these latter global parameters will be used in the next sections, when considering more simplified modelling strategies, and might be useful to other researchers for comparison purposes.

The values inferred using the aforementioned models are summarised in Table 2.

\subsection{Shake-table test simulation and summary of results}

In the following, the capabilities of the reference AEM model, developed using the modelling strategies described in the previous sub-sections, are evaluated through a multi-step comparison with the experimentally-observed structural response of the full-scale building specimen LNEC-BUILD3. First, to preliminary assess the adequacy of the adopted assumptions on e.g. idealisation of construction details and material properties, the dynamic characterisation tests performed prior to the application of the base accelerograms were replicated numerically, and the ensuing undamaged first-mode fundamental periods of vibration $T_{u}$ compared. Then, measured and predicted displacement time-histories at various locations are compared against each other, as well as force-displacement hysteretic relationships at both floor and roof levels, and final damage pattern. Finally, aimed at quantifying the capabilities of the reference AEM model in capturing the overall effect of cumulative damage on the dynamic properties of the system, first-mode fundamental periods of vibration $T_{d}$ after the last testing phase were also compared.

For the undamaged building, measured $T_{u, E X P}$ was equal to $0.15 \mathrm{~s}$; analogous outcomes were predicted by the reference AEM model, which slightly underpredicted $(-7 \%)$ the experimentally-inferred first-mode fundamental period of vibration related to the undamaged state, being $T_{u, R E F}$ equal to $0.14 \mathrm{~s}$.

In Fig. 4a, the experimental and numerical hysteresis plots of overall base shear vs average first floor horizontal displacement are shown; it is observed that the reference model overestimated both energy dissipation and deformation capacity in the last cycles, although a seemingly acceptable agreement with experimental results in terms of initial/residual stiffness and overall lateral resistance could nonetheless be found. On the other hand, as shown in Fig. 4b, where experimental and numerical horizontal maximum displacement profiles at various height (i.e. first floor, roofline, top of the tall chimney) and locations of the southern squat wall (top) and tall chimney are compared, the AEM model was able to capture the measured deformations during the main testing phases (i.e. SC2-350\% to SC2-500\%, characterised by moderate to heavy damage (see Kallioras et al. 2020), albeit 
(a) Average first floor horiz. displacement [mm]

(b) Horizontal displacement [mm]

(c) Horizontal displacement [mm]

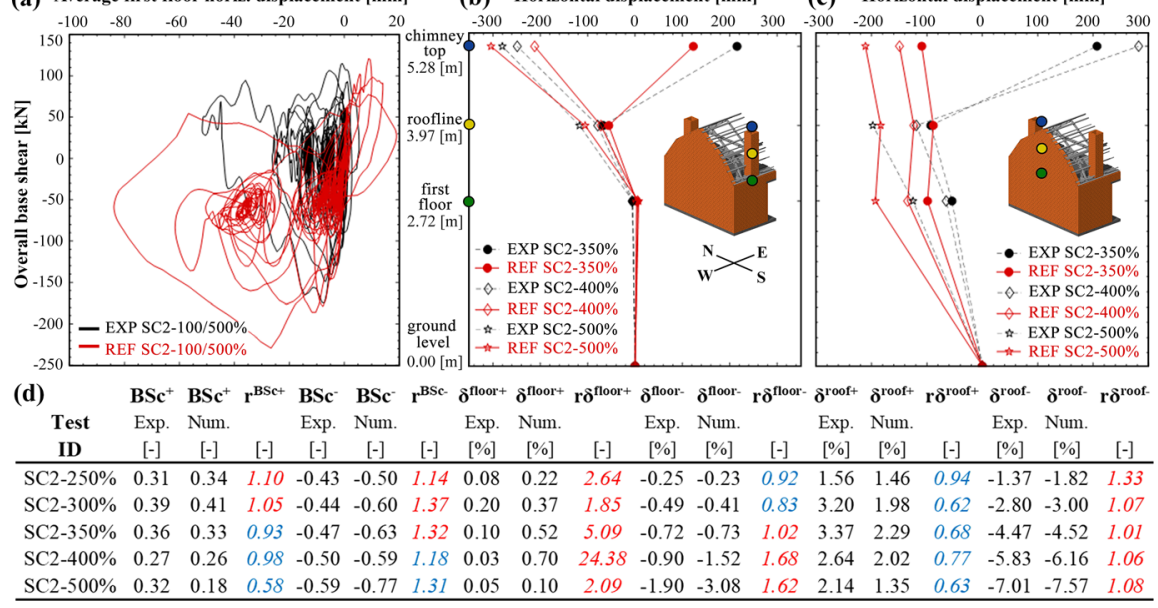

Fig. 4 Exp. vs num: a hysteretic curves, b South and West walls displacement profiles, $\mathbf{d} \max / \mathrm{min}$ key values

noticeably underestimating (approx. $-35 \%$ ) the maximum displacement recorded at the chimney top.

Immediately after the SC2-500\% positive acceleration peak, the modelled tall chimney-not collapsed experimentally-suffered extensive horizontal cracks at the interface with the roof, which eventually led to its collapse at the end of the record. Conversely, while the top portion of the short western chimney did collapse at the end of the testing phase SC2-400\%, its numerical counterpart (which in general exhibited significantly lower lateral displacements, see Fig. 4c) was still standing after SC2-500\%. It is nonetheless noted that, according to the post-test surveys conducted right after SC2-350\%, both chimneys exhibited substantial damage after SC2-400\%, i.e. where the whole building specimen was deemed to have reached near-collapse conditions. As noted by de Felice et al. (2017), the dissimilar ultimate behaviour of chimneys might be partly due to the intrinsic randomness of dynamic rocking responses, as well as to the high sensitivity, typically featured by discrete models, to even trivial perturbations of the geometry. This spurious phenomenon (also observable during tests - see e.g. Mouzakis et al. (2002), is particularly relevant for rigid-block-based collapse analysis, as argued by Papantonopoulos et al. (2002).

To further scrutinise the adequacy of predicted results, ratios among experimental and numerical global key quantities are reported in Fig. $4 \mathrm{~d}-\mathrm{r}^{\mathrm{BSc}}, \mathrm{r}^{\text {floor }}, \mathrm{r}^{\text {roof }}-$ defined as the ratio between actual and predicted positive/negative peak base shear coefficients $\mathrm{BSC}^{+}$and $\mathrm{BSC}^{-}$computed as the ratio between recorded base shear and the total weight of specimen, i.e. approx. $297 \mathrm{kN}$ ), floor and roof interstory drift ratios $\left(\mathrm{r}^{\text {floor }}\right.$ and $\mathrm{r}^{\text {roof }}$, where the interstory drifts $\delta^{\text {floor }}$ and $\delta^{\text {roof }}$ are computed as the relative average horizontal displacement of the considered floor/roof diaphragm divided by the story/roof height underneath) along both positive (superscript ${ }^{+}$, toward West) and negative (superscript ${ }^{-}$, toward East) shaking directions. Values reported in light blue colour indicate an underestimation by the model, with red being used instead to highlight model overestimation. Most of the computed $B S C$ values are close to unity, which is reassuring. The same applies to the experimental vs numerical diaphragm drift ratios, with the exception of that related to the positive first floor 
average displacement, largely overpredicted by the model towards the end of the testing sequence.

For what concerns the East and West façades, good agreement was found in terms of OOP displacements, whose time-histories (from SC2-250\% to SC2-500\%) depicted in Fig. 5a, b also appear to be in phase, especially from SC2-250\% to SC2-350\% (again, previous low-damage runs were herein purposely excluded from the comparison), where the deformation magnitudes were adequately accounted for numerically. From SC2-400\% to SC2-500\%, the simulated response started to diverge from the experimental one, overpredicting the residual OOP displacement; this can be attributable to the larger extent of cumulative damage computed by the AEM model, noticeable in e.g. the East façade as shown in Fig. 5c, where observed and numerical cracks (represented here has springs failed in tension) are graphically compared. This is further confirmed by the fact that the predicted fundamental period of vibration after SC2-500\%, i.e. $T_{d, R E F}=0.27 \mathrm{~s}$, was approx. $-3 \%$ lower than $T_{d, E X P}$, equal to $0.31 \mathrm{~s}$.

The above notwithstanding, and with the exception of the squat pier on the South façade for which an early diagonal shear failure (not observed during test) was predicted, locations, pattern and distribution of experimental cracks were satisfactorily reproduced, indicating that the main failure mechanisms exhibited by the URM components and those due to the local interaction with diaphragm systems were simulated reasonably well.

\section{Development of simplified multi-scale micro-models}

The impact that e.g. material properties (Mendes and Lourenço 2014), mesh size (Chácara et al. 2017), quasi-static vs dynamic loading type (Kappos et al. 2002), masonry panel (Quagliarini et al. 2017), bond pattern (Malomo et al. 2019) and diaphragm (Kollerathu and Menon 2017) idealisation might have on experimental vs predicted comparisons has been investigated and comprehensively documented. On the other hand, with the exception

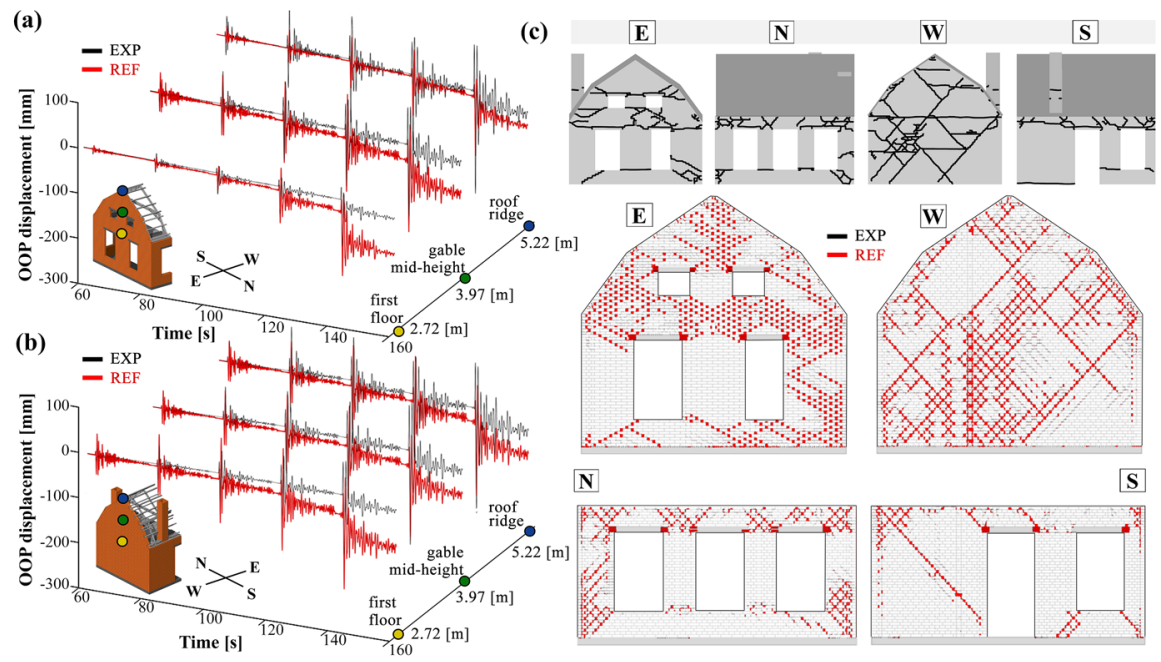

Fig. 5 Exp. vs num.: a East and b West walls OOP displacement time-histories, $\mathbf{c}$ final crack pattern 
of a few works investigating the effects of rigid element dimension (Pulatsu et al. 2020), loading history (Casolo and Uva 2013) and variability of interface spring parameters (Sarhosis and Sheng 2014), very limited research specifically related to micro-models of largescale URM structures has been conducted on the remaining abovementioned aspects, i.e. diaphragm and bond pattern modelling, as well as quasi-static vs dynamic loading type.

To try to address the aforementioned knowledge gap, three additional AEM micromodels of decreasing complexity (herein labelled M1, M2, M3) were therefore considered in this study and the obtained results compared with those of both the reference model and the experimental test on LNEC-BUILD3 (henceforth referred to as REF and EXP, respectively). The ensuing M1, M2, M3 models can be defined as "multi-scale", given that only some specific components, discussed below, were simulated with simplified modelling techniques. As further discussed in the next section, where the main outcomes of this sensitivity study are presented, in addition to the shake-table loading protocol used in the test (again SC1 signals were not considered herein), quasi-static pushover analyses, often preferred by applied researchers and practising engineers, were also performed to further broaden the impact of this study.

Summarised below are the main features of the additional simplified multi-scale models considered:

- In M1 (145,000 DOFs, see Fig. 6a), the roof system has been represented numerically as an equivalent continuous membrane with a linear elastic response and only deformable to IP shear actions, which accounts for the double-slope of the LNEC-BUILD3 gambrel roof, but neglects the explicit modelling of boards and purlins. The rationale behind this simplification lies in the fact that often the complexity of the timber roof of residential URM constructions (see e.g. Guerrini et al. 2019) translates in a tedious modelling exercise that requires the employment of significant human and computational resources. Further, when dealing with existing buildings, in certain cases inferring all the geometrical properties needed for devising a micro-model of the roof is either unpractical or simply not possible. Using this approach, local roof-to-wall interaction is neglected, which may result in a more conservative prediction of damage propagation of both longitudinal façades, if compared with the more refined approach used for REF.

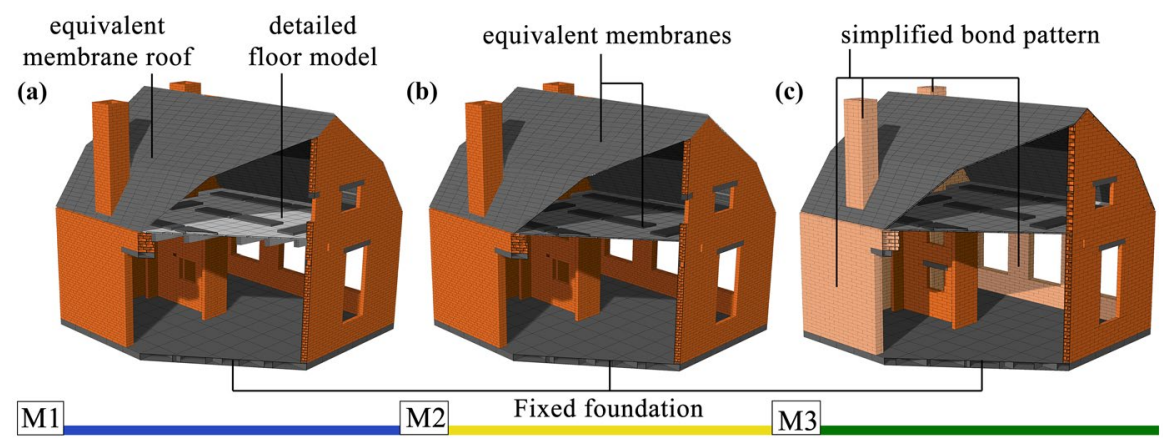

DECREASING MODELLING COMPLEXITY

Fig. 6 Screenshots of the AEM models of each of the simplified configurations considered, a M1, b M2, c M3 
- In M2 (98,000 DOFs, see Fig. 6b), the equivalent membrane described above is also used for the modelling of the first floor diaphragm, thus representing a further simplification with respect to M1. This represents a rather common assumption when using e.g. equivalent frame macroelement models; as for the point above, the possibility of adopting such a simplified approach would result in a reduced modelling and computational expense. Idealising the floor/roof systems as an equivalent membrane implies that the local diaphragms-to-wall interaction is neglected, which may lead to an underestimation of predicted damage extent, this time (because of the orientation of the joists of the diaphragms) of both longitudinal and transversal walls.

- In M3 (54,000 DOFs, see Fig. 6c), the influence of bond pattern modelling on the overall response is investigated; the Dutch-cross bond pattern of the double-wythe façades (orange colour) was replaced by a standard running brickwork (light orange colour), though maintaining the individual modelling of each single brick. Although it is wellestablished that if shear-compression IP loads are applied to URM members (intrinsically characterised by various degrees of anisotropy), they typically exhibit a high variability of initial lateral stiffness, ductility, lateral force capacity and deformation capacity due to the interaction between loading direction and bond pattern (Page 1981, 1983; Dhanasekar et al. 1985; Drysdale and Khattab 1995), the latter is seldom modelled explicitly and thus accounted for numerically. Further, recent micro-modelling outcomes (Malomo et al. 2019) revealed that the brick layout of Dutch cross-bond pattern URM members, which results in a steeper orientation of potential fracture planes through mortar joints if compared to other common brickworks, makes them more prone to brittle diagonal shear failures when considering single-leaf walls. This latter aspect usually translates in a reduced IP ultimate displacement capacity and base shear, which is what one would expect by the shake-table response of M2 with respect to that of M3. However, modelling a double-wythe wall with a running bond pattern (keeping the dimensions of the brick constant) implies the presence of a continuous vertical mortar joint between the two masonry leaves, which may cause delamination.

\section{Impact of modeling simplifications on numerical predictions}

The impact of the simplified modelling strategies presented in the previous sections is discussed and quantified in what follows. To this end, both experimental and detailed reference model results were compared to those obtained using M1, M2, M3 in terms of damaged-undamaged periods of vibration, force-displacement hysteretic response, final damage pattern. Required analysis times for M1, M2, M3 models were also compared with that of REF, to enable future users to pursue a more informed selection of potential modelling approaches. For the same reasons, quasi-static pushover analyses were also performed and the ensuing curves, obtained considering loading acting along both positive and negative longitudinal directions, compared to each other.

\subsection{Nonlinear dynamic analysis}

\subsubsection{In-plane hysteretic response}

The SC2 shake-table test loading protocol employed experimentally and already applied to the REF model was imposed also on the M1, M2, M3 simplified models. Before running 
such nonlinear dynamic analyses, however, the first-mode undamaged-state fundamental periods of vibration were computed in order to investigate potential differences related to the considered decrease of modelling refinement. As readily gathered by the $r^{T u}$ ratios (calculated as $T_{u, R E F-M 1-M 2-M 3}$ divided by $T_{u, E X P}$ ) summarised on the top left hand-side of Fig. 7a (light blue colour-model underestimates, red colour-model overestimates), only minor dissimilarities were found among the undamaged modal properties of the various models. Markedly different results were instead found for what concerns the damaged periods of vibration (whose decrease is mainly due to extent of springs failed in tension, with $T_{d, M 1}>T_{d, R E F}>T_{d, M 2}>T_{d, M 3}$, see $r^{T d}$ ) - this aspect, which will be further discussed in the following, is a direct consequence of the different shake-table responses predicted by the simplified models. From the same figure, it can also be gathered that different modelling strategies did lead to noticeably different results in terms of force-displacement hysteretic curves.

As shown in Fig. 7a, featuring the experimental and numerical hysteresis plots of overall base shear vs average first floor displacement, the M1 model (where the complex roof framing of LNEC-BUILD3 has been modelled as an equivalent membrane with shear modulus equal to $G_{\|}$, see Table) seems to noticeably underestimate (approx. $-25 \%$, see Fig. $7 \mathrm{~b}$ ) the maximum positive base shear capacity $\mathrm{BSc}^{+}$of the building specimen up to SC2-300\%, while $r^{B S c-}$ ratios with respect to the negative direction indicate an overestimation of $+34 \%$ for SC2-300\%. Results similar to those of REF were inferred in SC2-350\% and SC2-400\%. During SC2-500\%, instead, major differences were obtained in terms of $\mathrm{BSc}^{+}(+40 \%$ and $+25 \%$ compared to REF and M1 respectively). A factor that may have contributed to such dissimilarities is the fact that the use of an equivalent membrane implies that local

(a)

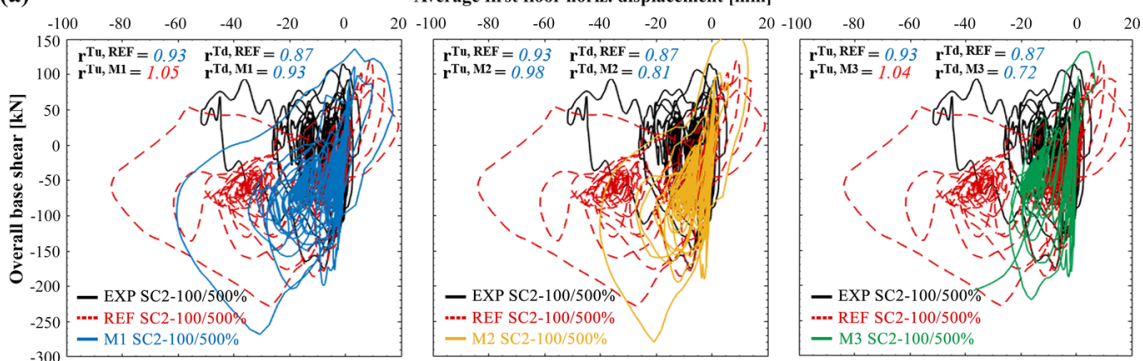

\begin{tabular}{|c|c|c|c|c|c|c|c|c|c|c|c|c|c|c|c|c|c|c|}
\hline & & & & & & & & & & & & & & & & & & \\
\hline $\begin{array}{c}\text { Test } \\
\text { ID }\end{array}$ & $\begin{array}{c}\text { Exp. } \\
{[-]}\end{array}$ & {$[-]$} & {$[-]$} & $\begin{array}{l}\text { Exp. } \\
{[-]}\end{array}$ & $\begin{array}{c}\text { Num. } \\
{[-]}\end{array}$ & {$[-]$} & $\begin{array}{l}\text { Exp. } \\
{[\%]}\end{array}$ & $\begin{array}{c}\text { Num. } \\
{[\%]}\end{array}$ & {$[-]$} & $\begin{array}{l}\text { Exp. } \\
{[\%]}\end{array}$ & $\begin{array}{c}\text { Num. } \\
{[\%]}\end{array}$ & {$[-]$} & $\begin{array}{l}\text { Exp. } \\
{[\%]}\end{array}$ & & {$[-]$} & $\begin{array}{l}\text { Exp. } \\
{[\%]}\end{array}$ & $\begin{array}{l}\text { Num. } \\
{[\%]}\end{array}$ & \\
\hline SC2-250\% & & & 0.67 & -0.43 & -0.47 & & & & & & & 0.38 & & & 0.05 & & & \\
\hline & & & & & & & & & & & & & & & & & & \\
\hline & & & & & & & & & & & & & & & & & & \\
\hline & & & & & & & & & & & & & & & & & & .1 \\
\hline & & & & -0. & -0.8 & 1.49 & & & & & & 17 & & & 11 & & & \\
\hline & & & & & & & & & & & & & & & & & & 0 \\
\hline & & & & -0 & & & & & & & & & & & .02 & & & 0 \\
\hline & & & & & & & & & & & & & & & & & & \\
\hline & & & & & & & & & & & & & & & & & & \\
\hline & & & 1.62 & -0 & -0 & 1. & & & 7 & & & 0.78 & & & 0.04 & & & 0.1 \\
\hline & & & & & & 1. & & & & & & 14 & & & .01 & & & 0.0 \\
\hline & & & 0.7 & & & & & & & & & 0.17 & & & 0.00 & & & 0.0 \\
\hline & & & & & & & & & & & & & & & & & & \\
\hline & & & & & & & & & & & & & & & & & & \\
\hline & & & & & & & & & & & & 0.92 & & & 0.02 & -7.0 & & \\
\hline
\end{tabular}

Fig. 7 Exp. vs num: a hysteretic curves for each of the configurations considered and $\mathbf{b}$ max/min key values 
roof-to-wall interaction is neglected, as well as the associated damage. With reference to the displacement response of the first floor, similar values to the REF counterparts were obtained. As expected, the most impacted experimental-to-numerical ratios were those related to the roof deformation, i.e. $r \delta^{\text {roof+ }}$ and $r \delta^{\text {roof- }}$; in this case, the simplifications introduced in M1 led to a substantial underestimation, with respect to both REF (from approx. $-50 \%$ to $-85 \%$ ) and measured (from $-55 \%$ to $-90 \%$ ) values.

For what concerns the M2 model, where both floor and roof diaphragms were idealised as equivalent membranes (with shear modulus $G_{\perp}$ and $G_{\|}$respectively, see Table), analogous magnitudes of $r^{B S c+}$ and $r^{B S c-}$ were obtained (with the exception of SC2-500\%, where M2 $\mathrm{BSc}^{+}$was $40 \%$ larger of that of M1). However, because of the simplified floor modelling, first floor deformability along both positive (from SC2-250\% to SC2-350\%) and negative (from SC2-250\% to SC2-500\%) directions has been underestimated (from $-5 \%$ to $-85 \%$ ). The M2 roof response, on the other hand, was similar to that predicted using M1.

Finally, with regards to the M3 model, although once again $B S c$ values appear comparable to that of the previous two simplified models, the accuracy in terms of roof deformability provided by the M3 model (devised starting from M2 and replacing the Dutch crossbond pattern of the double-wythe walls with a standard running bond brickwork) further decreased. Most noticeably, and as subsequently discussed in more detail (Sect. 5.1.3), because of a significant overestimation of the ground floor damage to both transversal and longitudinal façades due to delamination phenomena among the two adjacent leaves of double-wythe walls, the first floor deformability - especially from SC2-350\% to SC2$400 \%$ - was significantly overpredicted. This spurious response contributed to the early global collapse suffered by M3 after 8 s from the application of SC2-500\%, which was not observed experimentally. As a consequence, lower positive ultimate floor displacement capacity in the positive shaking direction was computed using M3 (approximately $-50 \%$ if compared with either test or REF results). On the other hand, the abovementioned damage localisation at the ground floor URM members led to a lower extent of simulated damage of the gables with respect to that detected experimentally, which inevitably resulted into a significant underestimation of roof displacement demand (ranging from $-80 \%$ to $-90 \%$ and $-95 \%$ and $-100 \%$ if compared with REF and test outcomes, respectively).

\subsubsection{Out-of-plane displacement response}

In Fig. 8 below, experimental and numerical (M1, M2, M3, REF) horizontal peak displacement profiles at various heights and locations of chimneys and South/West façades are compared. Again, one can readily appreciate the fact that the degree of numerical accuracy appears to be directly proportional to the level of modelling refinement. This is particularly evident for roof and chimney displacement responses, significantly underpredicted by M1, M2, M3 with respect to REF. What is discussed above is further confirmed by the plots included in Fig. 9a in terms of OOP displacement time-histories of East and West façades (roof-gable assembly, from SC2-250\% to SC2-500\%), where it can be observed how M1, M2, M3 also underpredicted their transversal deformability compared to both measured and REF results.

Similarly, from Fig. 9b, where the dynamic rocking response of both tall (South façade) and short (West façade) chimneys are reported in the form of top horizontal displacement vs time (from SC2-250\% to SC2-500\%), it is clear that the considered simplified modelling strategies have also had repercussions on the performance of the models with respect to the 


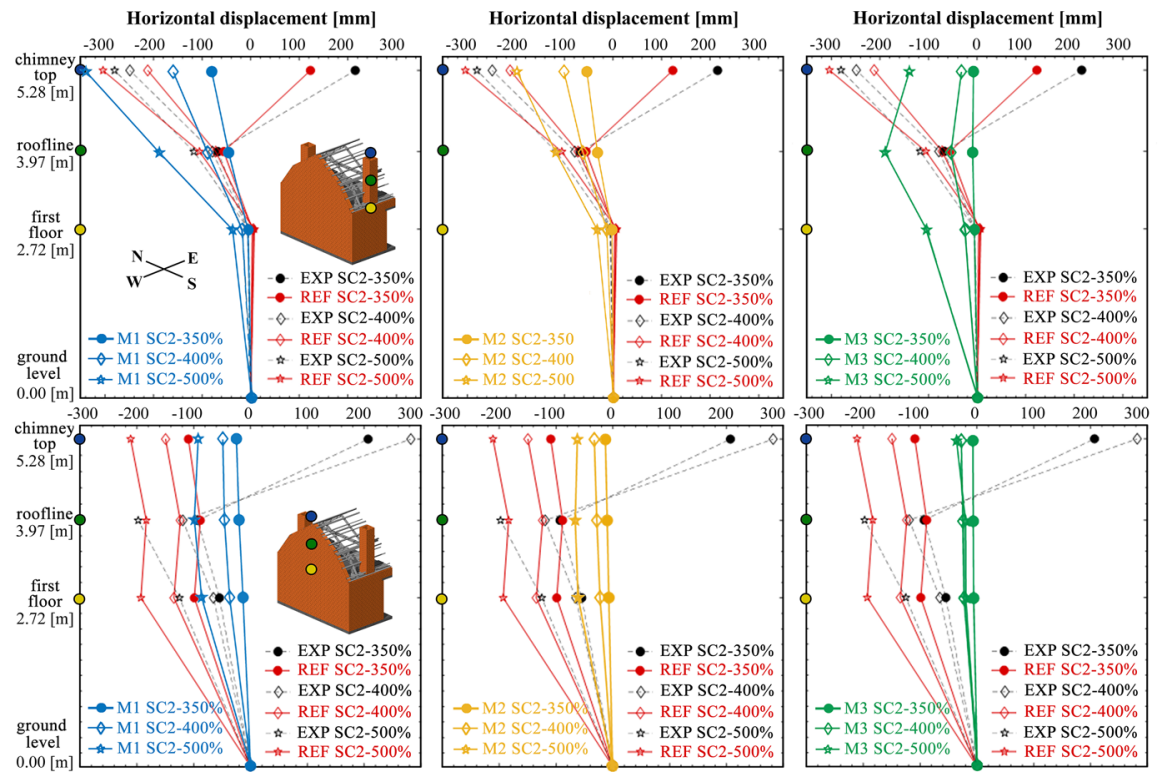

Fig. 8 Exp. vs num.: South and West walls displacement profiles for each of the configurations considered

(a)
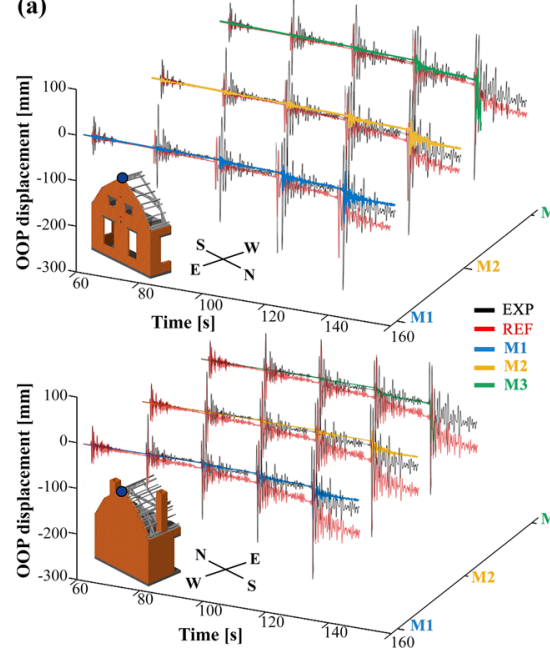

(b)
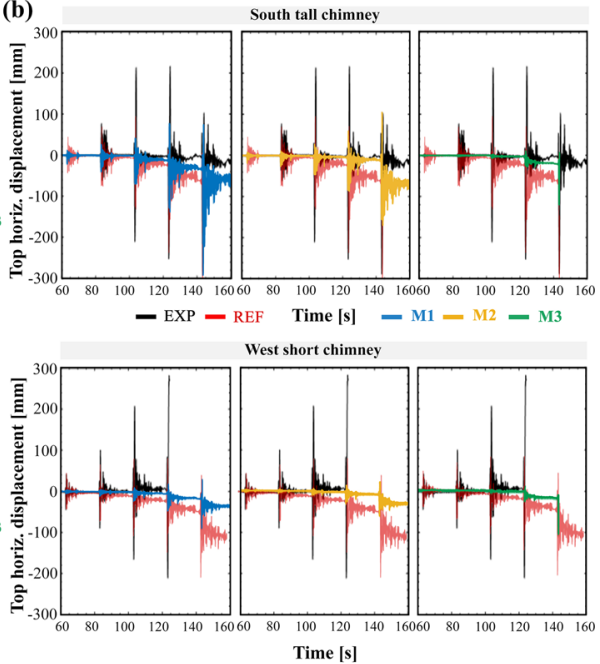

Fig. 9 Exp. vs num.: a East and West walls OOP displacement time-histories and b top horizontal displacement time histories of both tall and short chimneys for each of the configurations considered

simulation of the damage suffered by non-structural URM components, given that experimental values were noticeably underestimated. In this case, more convincing results were also obtained using REF (at least in terms of negative peak values), albeit not fully satisfactory and notwithstanding the fact that - unlike the other models - the latter predicted the collapse of the tall chimney which did not actually occur during the test (the short chimney 
did fail instead, while no analogous phenomena were simulated by none of the developed numerical models).

\subsubsection{Crack patterns}

With reference to the experimental vs numerical final damage comparison shown in Fig. 10, it is interesting to observe that the extent of predicted cracks is inversely proportional to the modelling refinement. In the East façade, pier-to-opening cracks were adequately captured by all the models, albeit with a different inclination in the case of M3. On the same façade, actual gable damage was overpredicted by REF and M1, particularly at the first floor level; in both the cases, this is related to the floor joists-to-wall local interaction, as confirmed by the central X-shaped crack pattern among ground and first floor openings. In REF, damage propagated also into the top of the East corner pier, something that was not observed experimentally. Slightly better results were obtained using M2, albeit damage was also overpredicted - as in M3 - in the middle of the central pier. In M3, cracks of the East façade were mainly localised at the ground level, causing the essentially undamaged gable to rigidly rotate around the first floor line, as confirmed by the horizontal cracks extending at that level. On the West façade, diagonal shear cracks were satisfactorily captured by M1 and M2, while delamination failures between inner and outer leaves of M3 occurred due to the presence of a continuous mortar joint among the two adjacent masonry wythes and because of the lack of interlocking (it is recalled that in this model a doubleleaf standard running bond pattern replaced the Dutch cross bond masonry texture). The same spurious phenomenon also affected the failure mode of the squat pier of the South
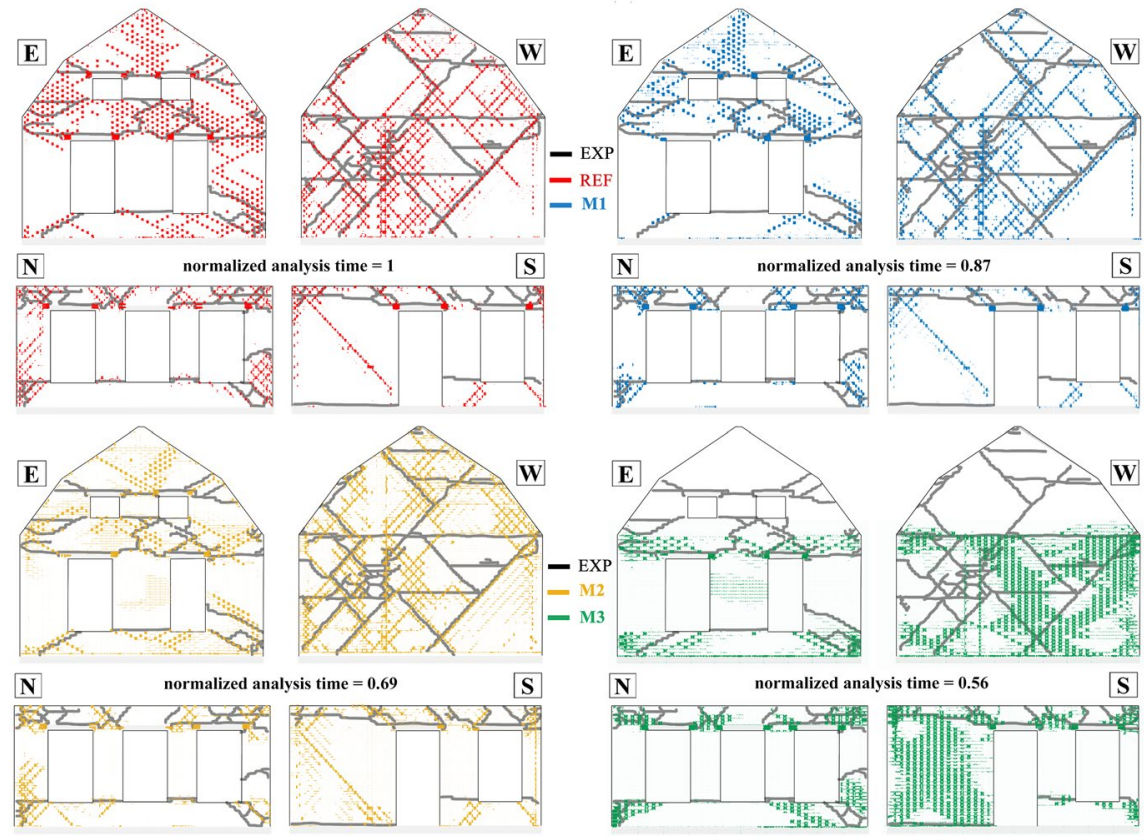

Fig. 10 Exp. vs num. final damage pattern for each of the configurations considered and required analysis time 
façade, which instead of diagonal shear exhibited base/top sliding mechanisms during the test.

Finally, as far as the North façade is concerned, geometrical constraints here made it easier for the models to simulate the actual damage pattern, albeit its extent (particularly at the interface with the first floor) seems to decrease with decreased complexity of the adopted diaphragm models.

To enable future comparisons and allow researchers to evaluate more accurately pro and cons of the proposed modeling strategies, on the top right-hand side of each of the numerical damage patterns depicted in Fig. 10, the time (normalised with respect to the REF one, i.e. $16 \mathrm{~h}$ ) required for each of the models to perform the whole loading protocol simulation is reported.

\subsection{Nonlinear static analysis}

Structural numerical assessment of URM structures via pushover analysis is often a preferred option when dealing with complex and large-scale systems, even more so when using a discrete micro-modelling approach (e.g. Pulatsu et al. 2016; Baraldi et al. 2018), so as to render it easier to benefit from the enhanced capabilities of detailed methods while constraining the computational expense. For this reason, in addition to the comparisons presented in the previous sub-section where differences among the various models were evaluated considering the dynamic incremental loading protocol employed for the shaketable of LNEC-BUILD3, in what follows mass-proportional pushover analyses on M1, M2 and M3 were performed along both the longitudinal directions, and the force-displacement curves obtained compared to those of the more detailed REF model. The analyses were stopped whenever the structure was unable to support vertical loads anymore. Interestingly, computational expense trends analogous to those presented in the previous sub-section were also obtained herein.

The selection of the force distribution pattern was guided by the work of Endo et al. (2017), who investigated the influence of lateral force distribution on the adequacy of pushover analysis results through comparison with both shake-table test outcomes and nonlinear dynamic FE simulations on various-scale URM building prototypes. These researchers concluded that, with respect to the URM specimens considered and notwithstanding the intrinsic limitations of pushover analyses, mass-proportional force distribution patterns were the most reliable choice.

As shown in Fig. 10a below, where overall base shear vs average horizontal first floor displacement curves of all numerical models are plotted against the corresponding experimentally-inferred hysteretic response, good agreements were found in terms of negative peak lateral force, with all the predicted results converging towards approximately the same value. Clearly, because of the fact that cyclic and cumulative damage was not accounted for numerically, actual progressive strength and stiffness degradation could not be replicated. For the same reasons, computed ultimate displacement capacity ratios between recorded and predicted values were unrealistically large - especially in the negative loading direction. Another factor possibly affecting the abovementioned dissimilarities is the adopted force-controlled loading protocol, an aspect not observed by Endo et al. (2017) but regarding which further investigations are perhaps warranted.

When considering the predicted peak positive base shear, M2 ended up exhibiting the larger maximum ( $+8 \%$ with respect to the test), while analogous values, more comparable with the experimental ones (yet still $+20 \%$ larger), were simulated by REF, M1 and M3. 
(a) Average first floor horiz. displacement [mm]
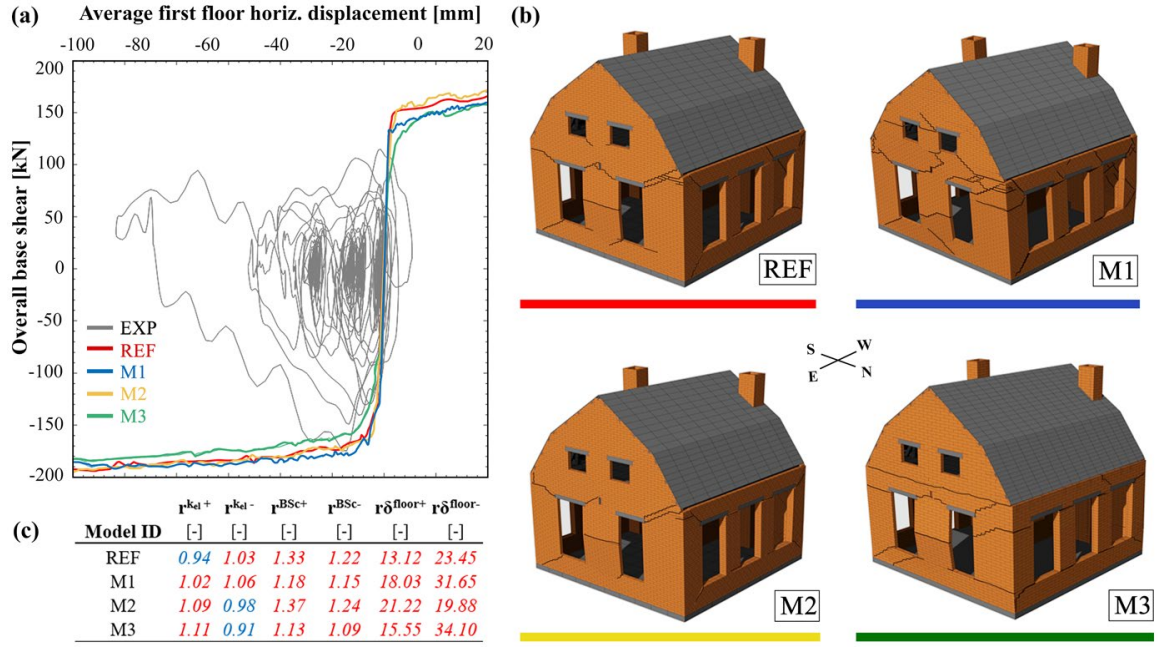

Fig. 11 a Experimental hysteretic response against predicted pushover curves, $\mathbf{c}$ final numerical deformed shapes (negative direction) for each of the configurations considered, $\mathbf{b}$ max/min key values

One of the main sources of these dissimilarities is the activation of different failure mechanisms, both IP and OOP, as can be gathered from Fig. 11b- where for the sake of simplicity, only the M1, M2, M3 negative 3D deformed shapes are depicted.

In Fig. 10c, ratios among REF and M1, M2, M3 key quantities, including $B S c, \delta^{f l o o r}$, and $k_{e l}$ (i.e. the initial elastic lateral stiffness of the system, calculated at the reference value of $10 \%$ BSc (see e.g. Costa et al. 2015), are summarised. Although less evident with respect to the previous section, the general trend seems to indicate that numerical accuracy decreases with decreased modelling refinement, and that simpler models tend to provide unconservative predictions.

\section{Conclusions}

The discrete micro-modelling of unreinforced masonry (URM) structures subjected to seismic loading offers several advantages with respect to standard continuous or simplified numerical approaches, including the possibility of representing explicitly damage initiation and propagation, failure mechanisms, local and global collapses, while accounting for outof-plane failures and damage due to wall-diaphragm local interaction. However, notwithstanding the growing interest in detailed simulation methods and the recent technological advances that render such complex analyses more feasible, the discrete micro-modelling of large-scale URM systems still represents an open challenge, entailing prohibitive computational expense, requiring a high degree of user specialisation and often material parameters not readily available in technical literature. For these reasons, it is often needed to decrease the level of detail with which some specific members or sub-structures are modelled.

In this work, the impact of modelling simplifications introduced in the detailed discrete micro-model of a full-scale URM building specimen (named LNEC-BUILD3) dynamically tested up until near-collapse conditions was assessed. The single-story full-scale prototype featured flexible timber diaphragms, a tall gable, two chimneys, two and single-wythe 
walls made of different brickworks and asymmetrical large ground floor openings. The response of the tested structure, being an assembly of components rather than a replica of an actual building, was characterised by multiple different responses, including e.g. the mechanical interaction between the central floor joist and the East wall and ensuing out-ofplane damage, in-plane/out-of-plane rocking of South and West chimneys, in-plane behaviour of North and South walls. The variety and complexity of these mechanisms make the use of macro-scale simulation techniques (e.g. Equivalent Frame models) challenging and not readily applicable, thus justifying the use of micro-models and rendering efforts for decreasing computational time even more important.

The results obtained with the detailed model (REF) were taken as a reference and compared with those from three nominally identical models in which, however, the idealisation of some specific structural elements was purposely simplified. In model M1, the complex roof framing (explicitly modelled in REF) was replaced by an equivalent continuous isotropic membrane, which constituted the basis from which to then create model M2, where also the first floor diaphragm was idealised as a membrane element. Finally, in model M3, the Dutch cross-bond pattern of the North-West-South façades was replaced by a standard double-leaf running bond brickwork, originally only present in the East wall.

Whilst all models catered for a reasonably accurate estimation of the evolution of the overall base shear capacity of the considered structure (average error in the range of $12 \%$, $19 \%, 18 \%, 26 \%$ with respect to experimental values for REF, M1, M2, M3, respectively), the introduction of simplifications in the modelling of the brickwork pattern in M3 led to the development of inaccurate crack patterns, failure mode, and, consequently, displacement response estimates in both in-plane $(-73 \%,-62 \%,-53 \%$ with respect to REF, M1, M2 first floor deformation) and out-of-plane $(-111 \%,-98 \%,-21 \%$ with respect to REF, M1, M2 West wall deformation) directions. Hence, notwithstanding the significant savings in model building effort and analysis time, the results obtained seem to suggest that it is best to explicitly reproduce the actual bond pattern when assessing the seismic response of a URM structure through a discrete element approach.

By contrast, the simplified modelling of the timber roof and floor assemblies did not compromise the computation of the in-plane displacement response (maximum negative displacement of M2 with respect to actual value was $-20 \%$, that of M1+17\%), though it did limit the accuracy with which damage patterns and out-of-plane failure mechanisms could be captured by the numerical model. As such, and considering also the difficulty in defining the mechanical properties of the components of such timber sub-assemblies, this modelling simplification may perhaps be considered in practical applications concerning the assessment of URM buildings with predominant in-plane response using discrete element approaches, especially when the accurate prediction of crack patterns is not necessarily paramount.

Acknowledgements The authors express their gratitude to all those at both the European Centre for Training and Research in Earthquake Engineering (Eucentre, Pavia, Italy) and the Laboratório Nacional de Engenharia Civil (LNEC, Lisbon, Portugal) that were involved in the testing campaign referred to in this paper for their precious assistance in accessing the test data. Finally, the authors are grateful to three anonymous reviewers whose constructive comments have undoubtedly contributed to a significant improvement of the overall quality of the manuscript.

Funding Open access funding provided by Università degli Studi di Pavia within the CRUI-CARE Agreement. 


\section{Declarations}

Conflict of interest The authors declare that they have no conflict of interest.

Open Access This article is licensed under a Creative Commons Attribution 4.0 International License, which permits use, sharing, adaptation, distribution and reproduction in any medium or format, as long as you give appropriate credit to the original author(s) and the source, provide a link to the Creative Commons licence, and indicate if changes were made. The images or other third party material in this article are included in the article's Creative Commons licence, unless indicated otherwise in a credit line to the material. If material is not included in the article's Creative Commons licence and your intended use is not permitted by statutory regulation or exceeds the permitted use, you will need to obtain permission directly from the copyright holder. To view a copy of this licence, visit http://creativecommons.org/licenses/by/4.0/.

\section{References}

Adhikari RK, D’Ayala D (2020) 2015 Nepal earthquake: seismic performance and post-earthquake reconstruction of stone in mud mortar masonry buildings. Bull Earthq Eng 18:3863-3896. https://doi.org/ 10.1007/s10518-020-00834-y

Applied Science International LLC. (2018) Extreme Loading for Structures

Aref AJ, Dolatshahi KM (2013) A three-dimensional cyclic meso-scale numerical procedure for simulation of unreinforced masonry structures. Comput Struct 120:9-23. https://doi.org/10.1016/J.COMPS TRUC.2013.01.012

Baraldi D, Reccia E, Cecchi A (2018) In plane loaded masonry walls: DEM and FEM/DEM models. A Critical Review Meccanica 53:1613-1628. https://doi.org/10.1007/s11012-017-0704-3

Berti M, Salvatori L, Orlando M, Spinelli P (2017) Unreinforced masonry walls with irregular opening layouts: reliability of equivalent-frame modelling for seismic vulnerability assessment. Bull Earthq Eng 15:1213-1239. https://doi.org/10.1007/s10518-016-9985-5

Block P, Ciblac T, Ochsendorf J (2006) Real-time limit analysis of vaulted masonry buildings. Comput Struct 84:1841-1852

Braga F, Dolce M (1982) A method for the analysis of antiseismic multi-storey masonry buildings (In Italian). In Proceedings of the 6th International Brick Masonry Conference. Rome, Italy.

Calvi GM, Moratti M, O'Reilly GJ et al (2019) Once upon a time in Italy: the tale of the morandi bridge. Struct Eng Int 29:198-217. https://doi.org/10.1080/10168664.2018.1558033

Cascini L, Gagliardo R, Portioli F (2020) LiABlock_3D: A software tool for collapse mechanism analysis of historic masonry structures. Int J Archit Herit 14:75-94. https://doi.org/10.1080/15583058.2018. 1509155

Casolo S, Uva G (2013) Nonlinear analysis of out-of-plane masonry façades: full dynamic versus pushover methods by rigid body and spring model. Earthq Eng Struct Dyn 42:499-521. https://doi.org/10.1002/ eqe. 2224

CEN European Committee for Standardization; (2004) EN 1995-1-1:2004, Eurocode 5. Design of timber structures. Part 1-1: General rules and rules for buildings. Brussels, Belgium.

Chácara C, Mendes N, Lourenço PB (2017) Simulation of shake table tests on out-of-plane masonry buildings. part (IV): macro and micro fem based approaches. Int J Archit Herit 11:103-116. https://doi.org/ $10.1080 / 15583058.2016 .1238972$

Costa AA, Penna A, Arêde A, Costa A (2015) Simulation of masonry out-of-plane failure modes by multibody dynamics. Earthq Eng Struct Dyn 44:2529-2549

Cundall PA (1971) A computer model for simulating progressive large-scale movements in blocky rock systems. In: Proceedings of the Symposium of the International Society of Rock Mechanics. Nancy, France.

D'Altri AM, Sarhosis V, Milani G et al (2019) Modeling strategies for the computational analysis of unreinforced masonry structures: review and classification. Arch Comput Methods Eng. https://doi.org/10. 1007/s11831-019-09351-x

D'Ayala D, Speranza E (2003) Definition of collapse mechanisms and seismic vulnerability of historic masonry buildings. Earthq Spectra 19:479-509

de Felice G, De Santis S, Lourenço PB, Mendes N (2017) Methods and challenges for the seismic assessment of historic masonry structures. Int J Archit Herit 11:143-160. https://doi.org/10.1080/15583058. 2016.1238976 
Dhanasekar M, Kleeman PW, Page AW (1985) Biaxial stress-strain relations for brick masonry. J Struct Eng 111:1085-1100

Drysdale RG, Khattab MM (1995) In-plane behavior of grouted concrete masonry under biaxial tensioncompression. ACI Struct J 92:653-664. https://doi.org/10.14359/9660

El-Kashif KF, Maekawa K (2004) Time-dependent nonlinearity of compression softening in concrete. J Adv Concr Technol 2:233-247

Endo Y, Pelà L, Roca P (2017) Review of different pushover analysis methods applied to masonry buildings and comparison with nonlinear dynamic analysis. J Earthq Eng 21:1234-1255. https://doi.org/10.1080/ 13632469.2016.1210055

Furukawa A, Spence R, Ohta Y, So E (2010) Analytical study on vulnerability functions for casualty estimation in the collapse of adobe buildings induced by earthquake. Bull Earthq Eng 8:451-479. https://doi. org/10.1007/s10518-009-9156-Z

Galvez F, Giaretton M, Abeling S, et al (2018) Discrete Element modelling of a two-storey unreinforced masonry scaled model. In Proceedings of the 16th European Conference on Earthquake Engineering. Thessaloniki, Greece.

Gattesco N, Macorini L (2014) In-plane stiffening techniques with nail plates or CFRP strips for timber floors in historical masonry buildings. Constr Build Mater 58:64-76. https://doi.org/10.1016/j.conbu ildmat.2014.02.010

Graziotti F, Penna A, Magenes G (2016) A nonlinear SDOF model for the simplified evaluation of the displacement demand of low-rise URM buildings. Bull Earthq Eng 14:1589-1612. https://doi.org/10. 1007/s 10518-016-9896-5

Graziotti F, Penna A, Magenes G (2019) A comprehensive in situ and laboratory testing programme supporting seismic risk analysis of URM buildings subjected to induced earthquakes. Bull Earthq Eng 17:4575-4599. https://doi.org/10.1007/s10518-018-0478-6

Grunwald C, Khalil AA, Schaufelberger B et al (2018) Reliability of collapse simulation - Comparing finite and applied element method at different levels. Eng Struct 176:265-278. https://doi.org/10. 1016/j.engstruct.2018.08.068

Guerrini G, Senaldi I, Graziotti F et al (2019) Shake-table test of a strengthened stone masonry building aggregate with flexible diaphragms. Int J Archit Herit 13:1078-1097. https://doi.org/10.1080/15583 058.2019 .1635661

Kallioras S, Correia AA, Graziotti F (2020) Collapse shake - table testing of a clay - URM building with chimneys. Bull Earthq Eng 18:1009-1048

Kappos AJ, Penelis GG, Drakopoulos CG (2002) Evaluation of simplified models for lateral load analysis of unreinforced masonry buildings. J Struct Eng 128:890. https://doi.org/10.1061/(ASCE)07339445(2002)128:7(890)

Karbassi A, Nollet M-J (2013) Performance-based seismic vulnerability evaluation of masonry buildings using applied element method in a nonlinear dynamic-based analytical procedure. Earthq Spectra 29:399-426

Kollerathu JA, Menon A (2017) Role of diaphragm flexibility modelling in seismic analysis of existing masonry structures. Structures 11:22-39. https://doi.org/10.1016/j.istruc.2017.04.001

Malomo D, DeJong MJ (2020) A Macro-distinct element model (M-DEM) for simulating the in-plane cyclic behavior of URM structures. Eng Struct 227:111428. https://doi.org/10.1016/j.engstruct. 2020.111428

Malomo D, DeJong MJ (2021) A Macro-Distinct Element Model (M-DEM) for out-of-plane analysis of unreinforced masonry structures. Eng Struct. https://doi.org/10.1016/j.engstruct.2021.112754

Malomo D, Pinho R, Penna A (2018) Using the Applied Element Method for modelling calcium silicate brick masonry subjected to in-plane cyclic loading. Earthq Eng Struct Dyn 47:1610-1630. https:// doi.org/10.1002/eqe.3032

Malomo D, DeJong MJ, Penna A (2019) Influence of Bond Pattern on the in-plane Behavior of URM Piers. Int J Archit Herit. https://doi.org/10.1080/15583058.2019.1702738

Malomo D, Pinho R, Penna A (2020a) Applied element modelling of the dynamic response of a fullscale clay brick masonry building specimen with flexible diaphragms. Int J Archit Herit 14:14841501. https://doi.org/10.1080/15583058.2019.1616004

Malomo D, Pinho R, Penna A (2020b) Simulating the shake table response of unreinforced masonry cavity wall structures tested to collapse or near-collapse conditions. Earthq Spectra 36:554-578. https://doi.org/10.1177/8755293019891715

Malomo D, Scattarreggia N, Orgnoni A et al (2020c) Numerical Study on the Collapse of the Morandi Bridge. J Perform Constr Facil 34:04020044. https://doi.org/10.1061/(ASCE)CF.1943-5509.0001428

Meguro K, Tagel-Din H (2000) Applied element method for structural analysis: Theory and application for linear materials. Struct Eng 17(1):21s-35s 
Meguro K, Tagel-Din H (2001) Applied Element Simulation of RC Structures under Cyclic Loading. J Struct Eng 127:1295-1305. https://doi.org/10.1061/(ASCE)0733-9445(2001)127:11(1295)

Meguro K, Tagel-Din H (2002) Applied Element Method Used for Large Displacement Structural Analysis. J Nat Disaster Sci 24:25-34

Mendes N, Lourenço PB (2014) Sensitivity analysis of the seismic performance of existing masonry buildings. Eng Struct 80:137-146. https://doi.org/10.1016/j.engstruct.2014.09.005

Mojsilović N (2011) Strength of masonry subjected to in-plane loading: a contribution. Int J Solids Struct 48:865-873. https://doi.org/10.1016/J.IJSOLSTR.2010.11.019

Mouzakis HP, Psycharis IN, Papastamatiou DY et al (2002) Experimental investigation of the earthquake response of a model of a marble classical column. Earthq Eng Struct Dyn 31:1681-1698. https://doi.org/10.1002/eqe.184

Page AW (1983) The strength of brick masonry under biaxial tension-compression. Int J Mason Constr 3:26-31

Page A (1981) The biaxial compressive strength of brick masonry. In Proceedings of the Institution of Civil Engineers. London, UK.

Pantò B, Cannizzaro F, Caliò I, Lourenço PB (2017) Numerical and experimental validation of a 3D macro-model for the in-plane and out-of-plane behavior of unreinforced masonry walls. Int $\mathrm{J}$ Archit Herit 11:946-964. https://doi.org/10.1080/15583058.2017.1325539

Papantonopoulos C, Psycharis IN, Papastamatiou DY et al (2002) Numerical prediction of the earthquake response of classical columns using the distinct element method. Earthq Eng Struct Dyn 31:1699-1717. https://doi.org/10.1002/eqe.185

Penna A, Lagomarsino S, Galasco A (2014) A nonlinear macroelement model for the seismic analysis of masonry buildings. Earthq Eng Struct Dyn 43:159-179

Petracca M, Pelà L, Rossi R et al (2017) Multiscale computational first order homogenization of thick shells for the analysis of out-of-plane loaded masonry walls. Comput Methods Appl Mech Eng 315:273-301. https://doi.org/10.1016/j.cma.2016.10.046

Portioli FPA (2019) Rigid block modelling of historic masonry structures using mathematical programming: a unified formulation for non-linear time history, static pushover and limit equilibrium analysis. Bull Earthq Eng. https://doi.org/10.1007/s10518-019-00722-0

Portioli FPA, Godio M, Calderini C, Lourenço PB (2021) A variational rigid-block modeling approach to nonlinear elastic and kinematic analysis of failure mechanisms in historic masonry structures subjected to lateral loads. Earthq Eng Struct Dyn eqe.3512. https://doi.org/10.1002/EQE.3512

Prakash PR, Pulatsu B, Lourenço PB et al (2020) A meso-scale discrete element method framework to simulate thermo-mechanical failure of concrete subjected to elevated temperatures. Eng Fract Mech 239:107269. https://doi.org/10.1016/j.engfracmech.2020.107269

Pulatsu B, Erdogmus E, Lourenço PB et al (2020) Simulation of the in-plane structural behavior of unreinforced masonry walls and buildings using DEM. Structures 27:2274-2287. https://doi.org/10.1016/j. istruc.2020.08.026

Pulatsu B, Bretas EM, Lourenço PB (2016) Discrete element modeling of masonry structures: Validation and application. Earthq Struct 11:563-582. https://doi.org/10.12989/eas.2016.11.4.563

Quagliarini E, Maracchini G, Clementi F (2017) Uses and limits of the equivalent frame model on existing unreinforced masonry buildings for assessing their seismic risk: a review. J Build Eng 10:166-182. https://doi.org/10.1016/j.jobe.2017.03.004

Raka E, Spacone E, Sepe V, Camata G (2015) Advanced frame element for seismic analysis of masonry structures: Model formulation and validation. Earthq Eng Struct Dyn 44:2489-2506. https://doi.org/ 10.1002/eqe. 2594

Saloustros S, Pelà L, Cervera M, Roca P (2018) An enhanced finite element macro-model for the realistic simulation of localized cracks in masonry structures: a large-scale application. Int $\mathbf{J}$ Archit Herit 12:432-447. https://doi.org/10.1080/15583058.2017.1323245

Sangirardi M, Liberatore D, Addessi D (2019) Equivalent frame modelling of masonry walls based on plasticity and damage. Int J Archit Herit 13:1098-1109. https://doi.org/10.1080/15583058.2019.1645240

Sarhosis V, Sheng Y (2014) Identification of material parameters for low bond strength masonry. Eng Struct 60:100-110. https://doi.org/10.1016/j.engstruct.2013.12.013

Silva V, Akkar S, Baker J et al (2019) Current challenges and future trends in analytical fragility and vulnerability modeling. Earthq Spectra 35:1927-1952

Snoj J, Dolšek M (2020) Pushover-based seismic risk assessment and loss estimation of masonry buildings. Earthq Eng Struct Dyn 49:567-588. https://doi.org/10.1002/eqe.3254

Tagel-Din H (1998) A new efficient method for nonlinear, large deformation and collapse analysis of structures. PhD Dissertation, University of Tokyo 
Thamboo JA, Dhanasekar M (2016) Behaviour of thin layer mortared concrete masonry under combined shear and compression. Aust J Struct Eng 17:39-52. https://doi.org/10.1080/13287982.2015.1116181

Tomassetti U, Correia AA, Graziotti F, Penna A (2019) Vulnerability of roof systems combining URM gable walls and timber diaphragms. Earthq Eng Struct Dyn. https://doi.org/10.1002/eqe.3187

Tomaževič M (1987) Dynamic modelling of masonry buildings: storey mechanism model as a simple alternative. Earthq Eng Struct Dyn 15:731-749

Vanin F, Penna A, Beyer K (2020) A three-dimensional macroelement for modelling the in-plane and outof-plane response of masonry walls. Earthq Eng Struct Dyn. https://doi.org/10.1002/eqe.3277

Vasconcelos G, Lourenço PB (2009) In-plane experimental behavior of stone masonry walls under cyclic loading. J Struct Eng 135:1269-1277. https://doi.org/10.1061/(ASCE)ST.1943-541X.0000053

Wilson A, Quenneville PJH, Ingham JM (2013) In-plane orthotropic behavior of timber floor diaphragms in unreinforced masonry buildings. J Struct Eng 140:04013038

Publisher's Note Springer Nature remains neutral with regard to jurisdictional claims in published maps and institutional affiliations.

\section{Authors and Affiliations}

\section{Mattia Calò $^{1}$ - Daniele Malomo ${ }^{2}$ (D) Giammaria Gabbianelli ${ }^{3} \cdot$ Rui Pinho ${ }^{1}$ (D}

Mattia Calò

mattia.calo01@universitadipavia.it

Daniele Malomo

daniele.malomo@mcgill.ca

Giammaria Gabbianelli

giammaria.gabbianelli@iusspavia.it

1 Department of Civil Engineering and Architecture, University of Pavia, 5 Via Adolfo Ferrata, Pavia, Italy

2 Department of Civil Engineering, McGill University, 817 Sherbrooke Street, Montréal, Québec, Canada

3 Scuola Universitaria Superiore IUSS Pavia, 15 Piazza della Vittoria, Pavia, Italy 